\section{This should not be the end for terminator technology in GM crops}

Sir-Monsanto's decision to abandon 'terminator' technology has been welcomed by those concerned about the genetic modification of food crops. The public perception is that this technology would force farmers in the developing world to purchase expensive seed year after year from multinational conglomerates. Although this is an important consideration, such technology might also have beneficial consequences, because ensuring the sterility of genetically modified (GM) crops could offer an important mechanism for environmental containment. By genetically engineering sterility, one could ensure that GM plants could not spread or crosspollinate with naturally occurring varieties.

The paradigm of sterility/incompetence is not new. The laboratory molecular biologist is all too familiar with containment, both at the physical and the biological level. In the 1970s there were fears that genetic engineering would result in the release of 'horror pathogens'. These fears were countered by the engineering of replicationincompetent vectors and disabled host organisms unable to grow outside the lab. This principle has been extended to the situation where molecular biology is used to treat human disease - gene therapy where ensuring replication incompetence of viruses has been an important regulatory hurdle for virally mediated gene transfer.

Concerns about cross-fertilization have featured frequently in the UK media, and have been countered mainly by arguments about physical distance, such as how far bees can fly. It is surprising that the lessons learned in applying molecular techniques to contain GM organisms in the lab have not been applied to agricultural biotechnology. Such features should be placed high on the agenda of policy-makers and those in industry trying to persuade us of the safety of their products. Although there are moral and social dilemmas surrounding 'terminator' technology, these techniques should not be discarded without further reflection.

Andrew Jackson, Chris Inglehearn

Molecular Medicine Unit, University of Leeds,

St James's University Hospital, Leeds LS9 7TF, UK

\section{Weighing up the threat to the world's corals}

Sir-A. J. van Loon's Correspondence, "Corals resist extinction by global warming", shows how two correct, but unrelated and incomplete, statements can lead to false conclusions ${ }^{1}$. Missing pieces in his reasoning include the different genetic base of corals past and present, the amount of temperature change to which corals can adapt, and the role of human-caused stresses.

The corals living during warmer conditions before the Pliocene-Pleistocene transition were different species from those alive today. The start of the Ice Ages saw a period of species extinction and origination $^{2}$. Today's corals are descendants of the most cold-tolerant corals that survived glacial episodes, while corals adapted to high temperatures largely vanished.

The upper temperature limits of modern corals have been determined experimentally by many researchers, starting with Mayor ${ }^{3}$ and Yonge and Nicholls ${ }^{4}$. They showed that only a few degrees of warming above normal maximum temperatures bleached and killed most corals, and found no behavioural or physiological capacity to adapt to higher temperatures. Subsequent research has refined but not changed their key conclusions ${ }^{5-9}$.

Extinct species were once able to adapt to warmer conditions than extant corals can tolerate, and presumably modern corals could do so again if there were sufficient evolutionary time and sufficiently slow rates of change. But fossil corals evolved in a world without humanaccelerated change. Coral temperature tolerance thresholds are now being exceeded worldwide, and rates of temperature change currently under way dwarf'natural' rates.

It is hardly surprising that modern corals are incapable of rapidly re-evolving the tolerance of high temperatures that their ancestors appear to have lost millions of years ago. Exponentially increasing anthropogenic pollution - in the form of greenhouse gases, nutrients, pathogens, sediments and other stresses - makes it very unlikely that corals will be able to adapt to a 'greenhouse world' quickly enough to survive, despite wishful thinking in Nature.

\section{Thomas J. Goreau}

Global Coral Reef Alliance, 324 Bedford Road, Chappaqua, New York 10514, USA

Sir - Van Loon ${ }^{1}$ argues that, just because coral reefs survived the geological past, global change is not a threat to them. It surely depends on the time-scale over which such change occurs. Corals survived sea-level fluctuations, in particular rapid drowning at the last glacial termination, but there are indications that reefs took 1,000 years to become re-established on the new shelves ${ }^{10}$.

Today's reef bleaching can be compared to what happened at the Cretaceous/ Tertiary boundary, when carbon dioxide and temperature levels rose shortly after the asteroid impact. Spectacular shell abnormalities are present in reef foraminifers today ${ }^{11}$, and similar effects occurred just after the boundary ${ }^{12}$. Reefs took about 10 million years to recover, mainly by recolonization by small corals or deep-sea forms ${ }^{13}$.

Reef decay will probably not be so great in the future, but the geological record gives a taste of what may be to come.

M. Pecheux

IUFM, Nice University,

15 rue des Roses, 06000 Nice, France

1. van Loon, A. J. Nature 400, 708 (1999).

2. Budd, A. F. \& Johnson, K. G. Proc. 8th Int. Coral Reef Symp. 1, 423-428 (1997).

3. Mayor, A. G. Carnegie Inst. Wash. Pap. Mar. Biol. 12, 175-178 (1918).

4. Yonge, C. M. \& Nicholls, A. G. Great Barrier Reef Expedition Sci. Pap. 1, 135-211 (1931).

. Jokiel, P. L. \& Coles, S. I. Coral Reefs 8, 155-162 (1990).

6. Williams, E. H. \& Bunkley-Williams, L. Atoll Res. Bull. 335, 1-71 (1990).

Glynn, P. W. Trends Ecol. Evol. 6, 175-179 (1991).

8. Goreau, T. J. \& Hayes, R. L. Ambio 23, 176-180 (1994).

9. Goreau, T. J., McClanahan, T., Hayes, R. \& Strong, A. Conserv. Biol. (in the press).

10. Davies, P. et al. Proc. 5th Int. Coral Reef Conf. 3, 95-103 (1988)

11. Hallock, P. et al. J. Foram. Res. 25, 280-286 (1995).

12. Gerstel, J. et al. Paleoceanography 1, 97-117 (1986).

13. IGCP Project 286: Early Paleogene Benthos (UNESCO, Paris, 1989).

\section{Who's doing what in US protein initiative}

Sir - We read with interest the article describing the initiative by the National Institute of General Medical Sciences (NIGMS) to assemble structural information on at least 10,000 proteins over the next five years (Nature 400, 494; 1999). What this otherwise informative article did not make clear was the role of other US government partners in supporting the basic structural-biology infrastructure upon which this initiative is built — particularly the Offices of Biological and Environmental Research and Basic Energy Sciences of the Department of Energy (DOE), and the National Science Foundation (NSF).

Additionally, the DOE has played a major role in developing structural genomics in the United States. Over the past decade the National Institutes of Health (NIH), NSF and DOE have substantially increased access to synchrotron light sources for protein crystallography through a series of initiatives. The agencies are implementing further improvements at the synchrotrons that will provide the capacity needed to reach the ambitious goals of the Protein Structure Initiative (PSI). The DOE is supporting structural genomics efforts at Brookhaven, Los Alamos and Lawrence Berkeley National Laboratories. In January 1998, the DOE 
helped to organize a meeting at Argonne National Laboratory which triggered subsequent meetings at NIH and elsewhere that resulted in the PSI.

All three agencies support the Protein Data Bank, which is managed by the Research Consortium for Structural Bioinformatics to provide access to the more than 10,000 known protein structures. The addition of 10,000 new structures through the PSI will provide the information needed to define the several thousand key protein folds that, in turn, should enable classification of proteins into functional categories. The contributions of each of these agencies (and those of several nonfederal organizations) will be needed to enable the NIGMS initiative to succeed. Marvin Cassman ${ }^{\star}$, Ari Patrinos $\dagger$ ${ }^{*}$ Director, National Institute of General Medical Sciences, National Institutes of Health, Bethesda, Maryland 20892-6200, USA

$\dagger$ Associate Director for Biological and Environmental Research, Department of Energy, 19901 Germantown Road, Germantown, Maryland 20874-1290, USA

\section{Search is on for better search engines}

Sir-Steve Lawrence and C. Lee Giles stated in their Commentary that most of the popular search engines index only about 7-16 per cent of the World-Wide $\mathrm{Web}^{1}$. This is alarming, as many scientific web pages containing important data may never be discovered. As the web grows it is going to become increasingly difficult for general search engines to give comprehensive coverage. The answer to the problem could be the development of subject-specific search engines able to cover most of the contents within that subject.

Most currently available subjectspecific lists and indexes are maintained by humans. Many of them are merely collections of web addresses and lack contextbased relevance ranking and retrieval of results in multivariate combinations. What is needed are search engines that could traverse through pages at the last level in a subject-specific website. They would be able to do this as the numbers of such sites would be within manageable limits. Crawlers or robots traversing through such a subject-specific web subset could build up a comprehensive and complete bank of keywords. In turn, such keyword-mounted crawlers would efficiently and more frequently screen the last-level page of the site.

Subject-specific search engines would be able to maintain the freshness of the hits, as the crawlers would check a manageable number of specific web pages more frequently than they would by moving through the entire web.

Mike Gardner ${ }^{2}$ has rightly suggested that we need science-oriented search engines with sets of scientific metadata, as metadata are the key to better searching. Together with that proposal, an approach similar to peer-reviewing of scientific publications could be applied for categorizing and evaluating web pages based on their content, quality and subject-specificity. It would be feasible to use algorithms and rule-based expert systems to check contentrichness, subject-specificity and freshnessbased context-relevance ranking for retrieved results.

Millions of dollars need to be invested in developing search engines. This investment could be cost-effective if it resulted in an almost zero noise-to-signal ratio and precise but comprehensive subject-relevant hits. The development work should be done in the academic sector, but the completed search engines would have commercial potential, and would generate more revenue than general search engines because of their subject-specificity.

Development of subject-specific search engines would satisfy the growing demand for the latest, precise, value-added, noisefree hits with a high level of subject relevance. Many such search engines together would be able to index most of the WorldWide Web.

Vishwas Chavan

Centre for Cellular and Molecular Biology, Uppal Road, Hyderabad 500 007, India

1. Lawrence, S. \& Giles, C. L. Nature 400, 107-109 (1999). 2. Gardner, M. Nature 401, 111 (1999).

\section{Japan builds bridges to rest of the world}

Sir-Your Opinion and News article about research in Japan raise an important and timely issue (Nature 401, $309 \& 314$; 1999). A focus on higher quality rather than quantity of scientific output, and more emphasis on cooperation with researchers abroad, are indeed important goals for Japanese science. But unfortunately the articles did not compare the Japanese situation with that elsewhere.

You report, for example, that 40 per cent of researchers submit papers only to Japanese journals, which is said to reflect insularity. But how can the reader draw such a conclusion without knowing comparable numbers for other countries? I would not be surprised if 40 per cent of researchers in the United States, the United Kingdom or Germany published only in national journals. And you did not mention that a considerable number of Japanese journals publish articles only in
English, which is surely an attempt to reach readers abroad.

It is interesting to learn that 40 per cent of researchers submit papers only to Japanese publications, while 34.1 per cent also submit to international journals. Does that mean that 25.9 per cent only publish in overseas journals? If true, this would show that there are many internationally minded Japanese researchers.

You do a good job of pointing out weaknesses and important goals for Japanese research. But your omission of comparative numbers for elsewhere in the world does not allow readers to see the problem in its true proportions. It could even be the case that your articles inadvertently promote prejudices about Japanese science, which would be unfortunate at a time when many Japanese research teams are striving to attract foreign scientists.

Philippe Buhlmann

Department of Chemistry, The University of Tokyo, Hongo 7-3-1 Bunkyo-ku, Tokyo 113-0033, Japan

\section{Galileo had accurate vision of the Moon}

Sir - Martin Kemp writes that "the details of Galileo's cratered Moons are difficult to align precisely with actual features" ${ }^{\prime}$. I would like to draw readers' attention to the work of Ewen Whitaker ${ }^{2}$, a selenographer at the University of Arizona. Whitaker reviewed earlier efforts at identifying the features drawn by Galileo, and took special note of the important contributions of Guglielmo Righini, Owen Gingerich and Stillman Drake. He provided side-by-side comparisons of Galileo's drawings with modern photographs taken at the same lunar phases, and these provide striking support for his contention that Galileo did indeed observe, and record, very accurately.

Whitaker had examined the copperplate engravings of the first edition of Galileo's Siderius Nuncius and seven manuscript images, and he commented on "previously unnoticed differences between the manuscript and printed versions of Siderius Nuncius... In the original edition these engravings present a reasonably well-executed appearance, but subsequent editions utilize woodcuts, and the quality deteriorates very rapidly to the point where they are virtually unrecognizable as Moon images. Some of the disparaging remarks made about the drawings undoubtedly stem from examinations of these cruder images".

\section{W. Friedlander}

Department of Physics, Washington University, St Louis, Missouri 63130, USA

1. Kemp, M. Nature 401, 116 (1999).

2. Whitaker, E. J. Hist. Astron. 9, 155-169 (1978). 